\title{
ENGAGED INDIGENEITY
}

\section{Articulating, anticipating, and enacting tradition on Mauna Kea}

\author{
Greg Johnson
}

\author{
HE AHA LA HE KŪKULU, HE MAUNA \\ What is a pillar, a mountain \\ HE AHA LA HE KÜKULU, HE 'AHU \\ What is a pillar, an altar \\ HE AHA LA HE KÜKULU, HE PŌHAKU \\ What is a pillar, a rock \\ HE AHA LA HE KÜKULU, HE KANAKA \\ What is a pillar, a person \\ - Ka'i Kükulu, composed by Pualani Case ${ }^{1}$
}

\section{Holding space: engaged indigeneity between eruptions on Mauna Kea}

Volcanic metaphors should not be used lightly with reference to anything in Hawai'i. The potency of the land is all too real. Consider the eruption of 2018 that lasted for several months and reconfigured a large region of Hawai'i Island. It had been decades since a major eruption, but those who understand the 'aina (land) and its mo'olelo (stories) knew what to expect. Pressure had been building. The only question was when, where, and with what consequences an eruption would occur on the flanks of Mauna Loa, one of the two enormous mauna (mountains) that make up the island. The other monumental peak is Mauna Kea (aka Maunakea and Mauna a Wākea), which has not erupted in centuries, at least not geologically speaking. Culturally, it has been the site of two momentous eruptions in recent years, including one that is ongoing (as of April 2020). I am referring to widespread and highly visible protests over the TMT (Thirty Meter Telescope) project that took place in the summer of 2015 and the summer of 2019. This chapter focuses on this context, which happens to span the 


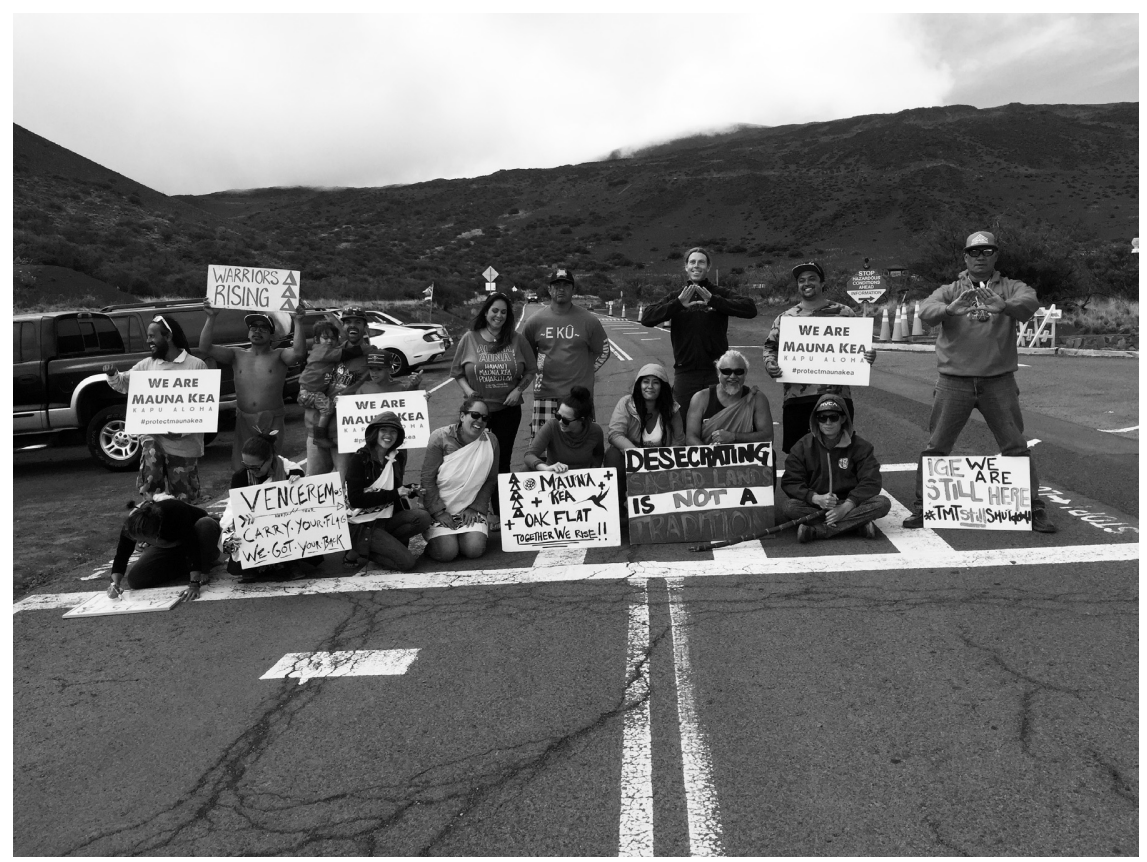

FIGURE 5.1 Kia'i (Protectors) on June 24, 2016, posing for the daily crosswalk picture on Mauna Kea.

duration of the INREL project. My analysis of the dispute is directly informed by involvement with INREL, the questions I have framed are inspired by the team's collective research trips and years-long conversations, and I was fortunate to receive real-time feedback from the team concerning portions of this chapter during their visit to Hawai' $i$ in 2018.

This chapter unfolds as follows. It opens with background regarding Mauna Kea, the TMT project, and resistance to it, sketching an account of the key issues and events leading up to the 2015 protest, which involved numerous arrests and served as a cultural catalyst in a range of registers. Once this groundwork is established, the core of the chapter turns to the time and space between the two protests in order to focus on the work of engaged indigeneity in a lower key through analysis of Kükulu: Pillars of Mauna a Wākea, an exhibit at the Hawaiian Cultural Center of Hāmākua. After addressing Kükulu, the chapter shifts to consider the 2019-2020 protest, which as I write is ongoing and of an unprecedented scale in modern Hawaiian history. For our purposes, this protest is instructive for a number of reasons, especially with regard to the way religious life and ceremonial action are foregrounded in the movement. Concluding, I return to key INREL-inspired questions to work through the role of religion - both on and off stage - in the Mauna Kea context and how this relates to indigenous religion(s) in a comparative frame. 
The choice to focus on the Kükulu exhibit as my core example of engaged indigeneity is in part a response to critics of the Mauna Kea movement who have suggested that it is a fad and will die down once the novelty of protest has worn off. Such a response fails to fathom the depth of connection many Hawaiians feel to the mauna, and it surely misconstrues the diachronic ebbs and flows of tradition in action. Traditions often persist in unexpected ways, their protagonists adapting to conditions in ways that merit attention. All too often indigeneity is studied in its peak expressions, its eye-popping manifestations, wearing its most media-ready face. Such a focus is important, to be sure, and scholars of religion are obviously drawn to maximal expressions of tradition. Taken too far, however, such a focus tends towards exoticism and even fetishisation. If our goal is in part to understand indigenous religion(s) in the round, then some of our attention should be diverted to the ways they 'hold space' between eruptions.

It is for this reason that I attend primarily to the time between the protests in order to explore what happens when the world is not directly watching. How are passions, resources - and, ultimately, tradition itself - cultivated and channelled during the sometimes long periods between episodes of indigeneity on display? With this approach, I seek to build on previous work I have done that explored the day-to-day grind of Hawaiian involvement in administrative law, primarily with regard to burial protections (Johnson 2014). My theoretical concerns in that context and here have do with the way movements are sustained 'off stage' (Scott 1990; Povinelli 2002; Niezen 2003) and what this down-swing in the dialectics of identity maintenance can tell us about the social life of indigenous religion(s) in a more general frame.

The direct carry-over from my earlier effort in this regard pertains most obviously to the contested case hearing regarding Mauna Kea, a quasi-legal administrative process that lasted from 2016-2017 and involved more than 20 Hawaiian petitioners and intervenors who gave over countless unheralded hours to holding space for Mauna Kea and holding up time vis-à-vis development of the TMT project (Johnson 2018). Their painstaking effort kept the movement alive at a time when it appeared to be waning. Some of the same people who persisted through that grim and arduous process are active on the front lines of protest now, garnering considerable attention at home and abroad. But had it not been for their efforts navigating tortuous state processes, there would likely not be such a robust movement unfolding on the mauna. In such contexts, tedious legal processes and forms of mass civil disobedience - especially in their dialectical unfolding - are rich fields for discerning the contours of indigenous religion(s) in action.

For all that the administrative and legal processes deserve analysis, my attention in this chapter is focused on another compelling way members of the Native Hawaiian community held space for Mauna Kea in the years between protests by means of staging a unique Kükulu exhibit, the explicit purpose of which was to keep the mauna front-and-centre in the community's consciousness during a relatively dormant phase of the movement. Core INREL categories (e.g., 


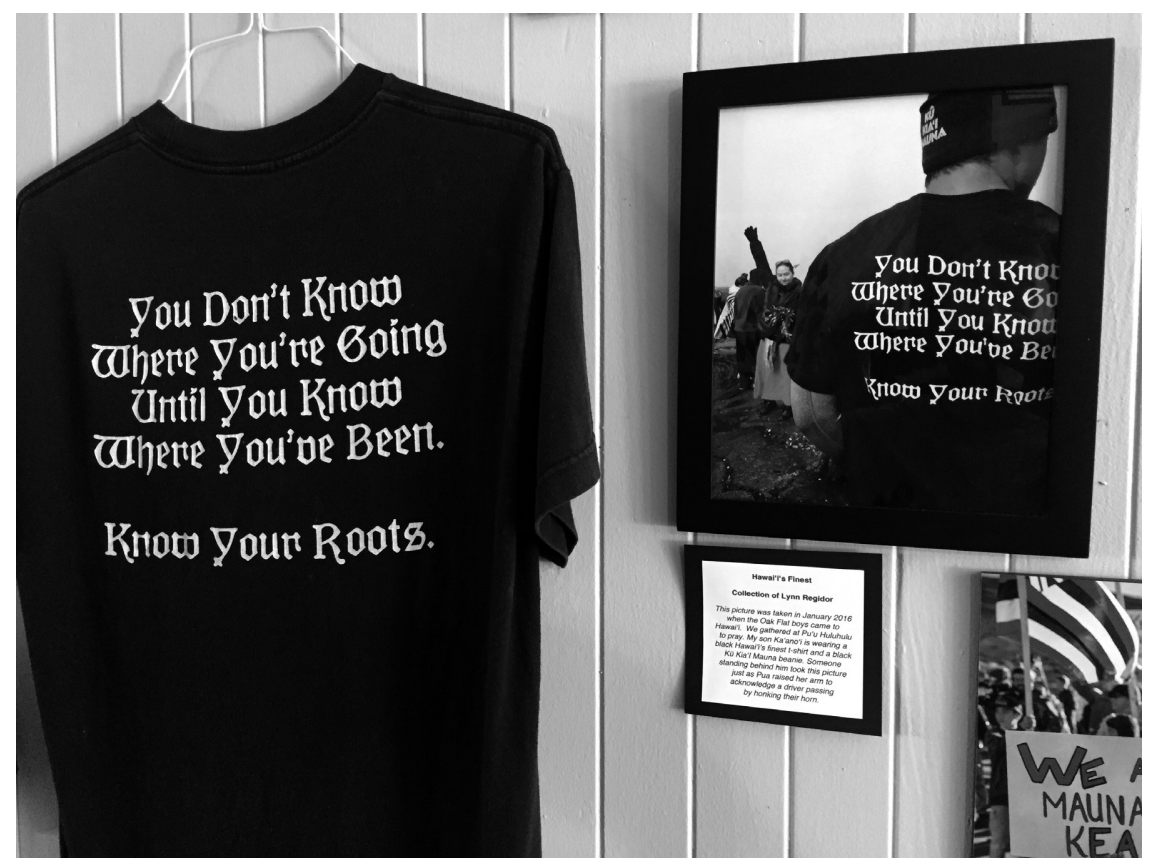

FIGURE 5.2 Images of images at Kūkulu.

sovereignty, mediation, translation, and performance), I suggest, are useful for understanding the work of Kukulu. In the course of illustrating this point, I employ the idiom of 'engaged indigeneity', by which I mean ultra-contemporary acts of indigenous self-fashioning and performative sovereignty. This framing language is intended to encourage insights about indigenous representation, especially with reference to questions that drill down to explore the specific ways religion is articulated in the unfolding present, with a debt to an interdisciplinary array of theorists, including Stuart Hall (1986), Angela Gonzales (1998), Tania Li (2000), James Clifford (2004), and Thomas Tweed (2006). Further, I hope to show how aspects of $K \bar{u} k u l u$ shed light on features of indigeneity in a comparative frame, at least some of the time in some places (Figure 5.2).

\section{Background to Mauna Kea-related issues}

Rising to 13,800 feet (4206 metres), Mauna Kea is the highest point in the Pacific Ocean and a mountain regarded as sacred by many Hawaiians. This majestic mauna and the cultural life sustained and perpetuated on its slopes are the beginning and end of Kükulu. I mean this in two senses: a historical sense, insofar as the exhibit is about protective actions by the community on behalf of the mauna, which I will describe shortly; I also intend to signify a pragmatic sense. The exhibit is a storehouse of tradition that began on and has returned to the mauna. 
The conceptual frame this dynamic establishes is critical. For here we are dealing with the intentional curation of protest objects as a site of memory and sentiment cultivation, but also in a more literal sense. Kükulu is where some implements of collective protest were stored until they were called into service once again during the summer of 2019. Questions about sign, symbol, materiality, and use value, for example, compound rather intensely in such a setting.

But why has the TMT project on Mauna Kea become such a flashpoint issue in the Hawaiian community? Critical information about the cultural background, protest actions, and legal history of the dispute has been published by a number of Hawaiian and ally scholars, including Noelani Goodyear-Ka'ōpua (2017), Marie Alohalani Brown (2017), Iokepa Casumbal-Salazar (2017), and Candace Fujikane (2019). My own contributions to this emerging literature include an INREL project essay about material religion and performativity in the 2015 protests (Johnson 2017); a piece reflecting on my role as a witness in the administrative proceeding regarding the construction permit (Johnson 2018); and a comparative piece written with Siv Ellen Kraft that juxtaposes three protests across a several-decade period (Kraft and Johnson 2018). Here I will sketch the most salient episodes that led up to the establishment of Kükulu.

Hawaiian lands have been subject to dispossession and desecration since the early 1800 s, a trend that accelerated intensely in the mid-1800s as non-Hawaiians laid hold of vast tracts of land through various means, including by way of legal machinations (Merry 2000; Osorio 2002). The overthrow of Queen Liliuokalani in 1893 and the illegitimate annexation of Hawai'i by the U.S. in 1898 exacerbated this trend. Industrial farming of sugarcane and other crops was another blow, as was the profound militarisation of the islands that took hold early in the 20th century and has not abated, often with shockingly disastrous consequences for the land and ocean. Homes, livelihoods, burial grounds, and sacred places have been damaged and lost throughout this history. But Hawaiians have remained culturally strong nonetheless and have built legal and political might in recent decades to complement their considerable cultural renaissance. Direct action protest has emerged as a staple of Hawaiian cultural life over the past 50 years, the focus of which ranges from protecting particular places and practices to articulating full-throated decolonisation agendas. The Mauna Kea movement sprung from the intersection of these vectors and also from something the state consistently under-estimates: Hawaiian religious sensibilities about place and kuleana (responsibility) that are uncompromising.

Many Hawaiians have a particularly strong felt sense of kuleana to Mauna Kea, as it holds a central place in their oral traditions as a kino lau (embodiment) of Wākea (Sky Father). It is also a long-time pilgrimage site that is home to numerous of $a h u$ (altars) and burials. It is understood to be Wao Akua (the realm of the gods), not a place for humans to linger, let alone develop. For these reasons, many Hawaiians have reacted strongly to the development of astronomical facilities and related infrastructure on Mauna Kea, which began in the 1960s. State and federal laws have offered little recourse for protection of Mauna Kea, 
which comes as no surprise to those familiar with U.S. land-use jurisprudence. As of 2019, 13 telescopes are located on the mountain, along with other scientific apparatuses and support structures. Many of these are proximate to or on top of recorded sacred sites, which has hurt and incensed many Hawaiians.

This is the context for widespread resistance to the plans of the State of Hawai' $i$ and the Thirty Meter Telescope Corporation to build an extremely large telescope (with a footprint of 5 acres and a height of 180 feet) on the northern plateau region, a previously undeveloped area near the summit of the mauna. Plans were first promulgated in the early 2000 s, resulting in legal challenges and other resistance, which came to a head in a 2011 contested case hearing (a quasi-legal administrative process). This process had little impact on development plans; by 2014 construction was slated to begin. In October of that year a groundbreaking ceremony was held at the site with various dignitaries attending from sponsoring entities and countries, including Japan, Canada, India, and various U.S. institutions. Hawaiian kia' $i$ (protectors) were aware of the event and sought to stop it and garner press attention for their cause. Lanakila Mangauil, a young teacher from Hāmākua, led the charge, storming onto the site of the ceremony in ritual garb, chanting, shouting, and otherwise bringing a stark halt to the proceedings. He helped spark a movement in the process. ${ }^{2}$

The state and TMT shelved construction plans for the winter and reinitiated attempts to build in April 2015. Construction vehicles were met by praying protestors who occupied the mauna in resistance and demonstrated a willingness to be arrested in support of the cause. Meanwhile, the emerging protest scene was receiving international social media attention and growing support from allies, including other indigenous groups. In the late spring of 2015 a group of kia' $i$ established an encampment on the mountain as a means to detect and stop construction vehicles coming up the mountain. Matters came to a head on 24th June, 2015, when state police attempted to escort construction vehicles up the mauna once again, which I witnessed directly. It was an eruption of cultural energies at a level not seen in Hawai'i for decades. Approximately 800 protestors stood in the road in ceremony, chanting, praying, and making offerings while deliberately stopping the vehicles. ${ }^{3}$ This set the stage for the ceremonially-grounded framework of the 2019 protest. Police arrested 11 people that day in attempts to clear the road, but protestors managed to prevail by rolling large rocks into the road making it impassable. The police capitulated and the kia'i celebrated. Subsequently, the governor declared a temporary halt to construction efforts.

Meanwhile, a legal case about the project was grinding through the courts. The suit was brought by kia'i who claimed that the state had issued the construction permit without proper consultation, let alone consent. ${ }^{4}$ In late 2015 the State Supreme Court ruled that the state had not conducted adequate consultation and remanded the matter to The Department of Land and Natural Resources (DLNR) for another contested case hearing. This process lasted a full year and involved 44 days of hearings. I was involved in a modest capacity as a witness for one of the intervenors, William Freitas (Johnson 2018). In the end, the 
DLNR approved the permit, all the while without having engaged in meaningful or sustained consultation, despite the length of the process. The kia' $i$ appealed the decision, and the case went back to the State Supreme Court. The Court affirmed the DLNR permit in late 2018, a decision that most observers expected based on precedent and the financial stakes, with the projected costs of construction estimated at $\$ 1.4$ billion dollars. ${ }^{5}$ The Kükulu exhibit took shape in this context, birthed in a waiting period between legal decisions and direct action.

\section{Exhibiting engaged indigeneity}

$K \bar{u} k u l u$ is humble, homespun, and utterly approachable. It is also, I will argue, a manifestation of representational sovereignty at the cutting edge of indigeneity. Let me describe the scene as I experienced it in the spring of 2018. The space is open and airy. Muffled sounds from the main street of sleepy Honoka'a town waft through the open doors of the Hawaiian Cultural Center of Hāmākua, the original home of the exhibit. A kitten naps on the porch, another on the hood of a car parked outside. Children from a Hawaiian language class chase one another on their way out the door. Given this bucolic setting, in what way is it also a frontline site of engaged indigeneity? Importantly, there is the wide-ranging content of the exhibit. This alone makes Kükulu significant in the context of Hawaiian cultural displays. Indeed, its range of materials, genres, and inviting aesthetics merit ranking Kükulu as 'serious' when compared to most contemporary cultural exhibits. Beyond these notable features, what strikes me most about the installation is its movement-based model of accretion and its function as an armoury. It is a moving storehouse of signs that was waiting for future deployment. That future came in 2019.

Let me unpack these two signal features of Kükulu. First, it was conceived by its curator, Pualani (Pua) Case, and her team as being of and for the kia' $i$ of Mauna Kea. Tourists, drifters, and the odd scholar are all welcome, to be sure, but the intended audience is the self-same as the subject of the exhibit, the kia' $i$, who recognised almost immediately that their protests in 2015 were historyin-the-making and engaged in various acts of in situ tradition formation. This project of collective self-fashioning and memory consolidation persisted after the protests on the mauna itself, on social media, at other protest sites such as Standing Rock, where numerous Hawaiians visited, and concertedly during the annual commemorations of the main protests. Pua Case and others decided that the movement deserved its own exhibition as a means to maximise and amplify the moment's significance through celebrating its people, songs, prayers, art, signage, and other objects.

Conceptualised thus, and in a Hawai'i Island spirit, the exhibit would need to be mobile so as to be available to people in each moku (region) of the island and to serve as a locus for their objects and memories. So Kükulu has been designed to travel, moving in turn to four representative moku over a span of several years. At each resting place the objects from that particular community will be added 
and foregrounded. The final disposition of the exhibit remains an open question, however. This is not due to a lapse in planning but has more to do with the ways kia' $i$ are keenly aware that they and Kükulu are plotted in an unfinished story insofar as the struggle over the TMT project is not yet resolved. For example, the exhibit will require further installations to accommodate the massive amount of material culture fashioned during the 2019 protest, and the exhibit is currently experiencing a relatively fallow period while some of its objects and their makers go back to mauna to protect once again. Indeed, the current exhibit space is used for staging supplies and as a logistical support centre for the movement. In this respect, Kükulu is an exhibit that has literally returned to its origins - repatriation in a radically indigenised key that hinges on questions of activation rather than claims to ownership or rights of possession. Signs from the walls of the exhibit wave in the crisp air of the mauna once again.

I find this tremendously compelling and instructive. Here we have a museum anticipating history rather than merely capturing it. This bespeaks the genius of contemporary indigeneity in the mode of Kūkulu. As activist Lākea Trask put it to me with regard to the prospect of renewed protests in 2018, "We will be out front of them this time" (Personal communication, Humu'ula, 26 March, 2018). This kind of claim is not only tactical, though it is that. I take it to be indicative of a zeitgeist. In this case, to be traditional is to be positioned ahead of and prepared for other kinds of historical forces and actors, and to have the confidence and traditional grounding to assume and hold that position, steadfastly. Indigeneity here reverses the would-be arch of causality, at least as imaged by the status quo of nation-states and their apparatuses. By all appearances, this approach to the future as a site of tradition-making is coming to pass on the flanks of the mauna.

\section{Bodies politic}

Before diving further into an analysis of the exhibit, an important facet of indigeneity in Hawai'i deserves to be noted here, for it has considerable ramifications for all aspects of the story I am telling. Namely, political leadership in Hawai' $i$ is radically acephalous. Some features of this headless body politic are the following: a recent but failing history of attempts to have a Native Hawaiian government recognised at the federal level (Kauanui 2013); special (if seldom acted upon) status and rights as articulated by the State Constitution; ${ }^{6}$ a statelevel entity, Office of Hawaiian Affairs, that is charged with managing resources and programmes for Native Hawaiians; a land management entity, Department of Hawaiian Home Lands, that is charged with making land grants and housing awards for Hawaiians of 50\% and greater blood quantum; and a bewildering array of state and county level positions designated for the purpose of 'community consultation'?

Individually and together, these entities and mechanisms do not amount to a functioning tribal government or its proxy. My purpose here is not to comment 
further on this situation in political terms other than to note the important fact that many Hawaiians are profoundly frustrated by attempts to manage their identities, lands, and futures. Out of this frustration a strong but internally variable sovereignty movement has emerged (Tengan 2008; Goodyear-Ka'ōpua, Hussey, and Wright 2014). For our purposes, the critical observation to make is that the fractured nature of Hawaiian political authority has corollaries and consequences in the realm of cultural representation. No one group controls or claims to control representations of culture and tradition. Representation is thus managed outside any formal mechanisms or constraints (see Teves 2018). As with all human activity, but in a particularly intense way, navigation and negotiation make all the difference in this context, including in the staging of museum displays.

\section{Space, realms, objects, words, and signs}

Kükulu has all the trappings one might imagine to be included in an exhibit devoted to a culture-based protest event. Here I will enumerate and briefly describe some of these features before moving to analyse several of the standout components of the exhibit. The exhibit is highly visual. Artwork and photographs bedeck the space. Also immediately notable are various clothing items, which range from ornate ceremonial garb to quotidian objects such as work boots. It is also a space of words, some recorded in audio formats, but many printed and posted on the walls. These include narratives of several varieties: traditional histories of the mauna; a history of the legal dispute; a micro-history of the protest actions; and so forth. Another presence of words is in the form of mele (song) lyrics, pule (prayers), and a range of oli (chants).

To provide concrete examples of the content of exhibit's many words and the way these words depict and set the larger frame of the exhibit, here I briefly consider two chants. The first, Oli Mauna Kea, is eminently local, a tribute to the mauna composed by Nona Beamer that centres the mountain thus in line 2: "Ka mauna ki'eki'e, i luna Kü kilakila (The mountain high above, standing in great majesty)". Taking my cue from this oli, I wish to emphasise up front that the exhibit foregrounds Mauna Kea in numerous ways, not least for the reason that the original exhibit was on the flanks of the mountain and in the moku (region) of Hāmākua, which includes its piko (summit). Due to this relationship, the people of the moku feel and exert a special kuleana (responsibility) to the mauna and display a reverence for it that veritably seeps from the walls of Kükulu. Beyond words, such as those in Beamer's oli, Mauna Kea is celebrated in the exhibit spatially. The exhibit is organised by wao (realms), which are represented vertically in Hawaiian cosmology and in the installation space. The top-most space honours various akua (deities) of the mauna, including Poliahu (Snow Goddess), Lilinoe (Mist Goddess), and Mo'oinonea (Lake Lizard Woman). Other deities are understood to inhabit the mauna and the Hawaiian world generally, including 
Kū, whom we will encounter later. But Hawaiian reverence has a fine-grained and place-specific texture, so the mauna goddesses receive primary attention in $K \bar{u} k u l u$ by means of banners hanging from the ceiling dedicated to each.

Next is the wao of the mauna itself. One cannot escape the horizon of the mauna in the exhibit. From wall-sized murals to photographs, the manua is omnipresent inside the exhibit, just as it is outside the door and in the Hawaiian cosmic imaginary. Then comes the Wao Kanaka (realm of humans), which occupies the lowest but most fully developed aspect of exhibit. In this way the exhibit is about and for local Native Hawaiians, but it is clear in situating them beneath other realms and in a subservient position of mâlama (care) relative to the other wao. It is this inverted frame of dominion that has yielded political and theological nuances in protest idioms and action. "We are Protectors not Protestors" - a phrase that echoed at Standing Rock - communicates this positionality as an ethos and imperative. Even while Native Hawaiians self-situate thus, Kükulu is manifestly focused on human action. From eye level on down, Wao Kanaka is the topos, which one encounters by moving randomly about. The exhibit space is not organised in a way that directs movement, at least not in any obvious way.

Wao Kanaka is itself a tiered domain. Ritual protocol (e.g., song, prayer, dance, and offerings) is foregrounded as it was in the 2015 protest and again in 2019-2020. Artistic production (prints, textiles, and sculpture) is the next most privileged class. Accounts of protest and legal actions follow. Of course each of these domains is not wholly separable from the others, but they are often marked and remarked upon as such by the exhibit organisers. In any case, I submit that this stratified yet imbricated arrangement is indicative of Hawaiian cultural stratigraphy in general. While there would be no exhibit if it were not for the protests and the legal struggles that underpin them, so too would it not be a particularly Hawaiian exhibit if those facts dominated experience of the space. Further, this articulation of ritual action, aesthetic production, and protective action configures many indigenous protest settings today, if in non-identical ways.

Now let us turn to a second oli (chant), as it shifts attention from the mauna to the human realm and its contemporary entailments. Consider the following eponymous chant, Oli Kükulu, composed by Pua Case, which has a distinctly outward thrust. It names the contemporary moment and the trans-indigenous engagements it entails.

Natives the backbone of Hawai' $i$

Relatives of the big ocean of Kiwa

Relations of the first nation of Turtle Island

Friends support from around the world

Pillars, the four cardinal points

We are beloved warriors,

We are strong (wearing our top knots on our heads)

Rise ... 
I am a mountain guardian, a standing rock, a sacred stone, a water Protector

Rise $^{8}$

Declared so emphatically in the oli, the theme of local-global networks is also unmistakable on some of the protest signs curated in the exhibit. These are not signs of signs. They are the actual signs used in the protests and immortalised in numerous newspaper pictures and in a huge number of videos easily found online. The signs are mostly slogan-based. Classics include, "We Are Mauna Kea”, "Kū Kia“i Mauna”, "Aloha for the Mauna", "Desecrating is Not a Tradition", and "Warriors Rising”. I am interested in sign making and staging, and the poetics of slogan craft, which has deep Hawaiian roots but also connections to global indigeneity and modern protest movements in general.

$\mathrm{Ku}$ is perhaps the most famous of Hawaiian deities. He lives at Kūkulu in his incarnation as Kūkia'imauna (Protector of the Mauna). Or at least one of his kino lau (manifestations) does in the form of a ki'i la'au (wooden idol or icon). Actually, Kükia'imauna has two ki'i in the exhibit. One is the ki'i crafted for and used during the protests (approximately 2 feet tall). The other is a bit larger and more ornate image of the image, with equal potential for activation (see Figure 5.3). Just this much tells us volumes about living Hawaiian tradition. For it is a particular Hawaiian way of being to manufacture gods in moments of crisis and to

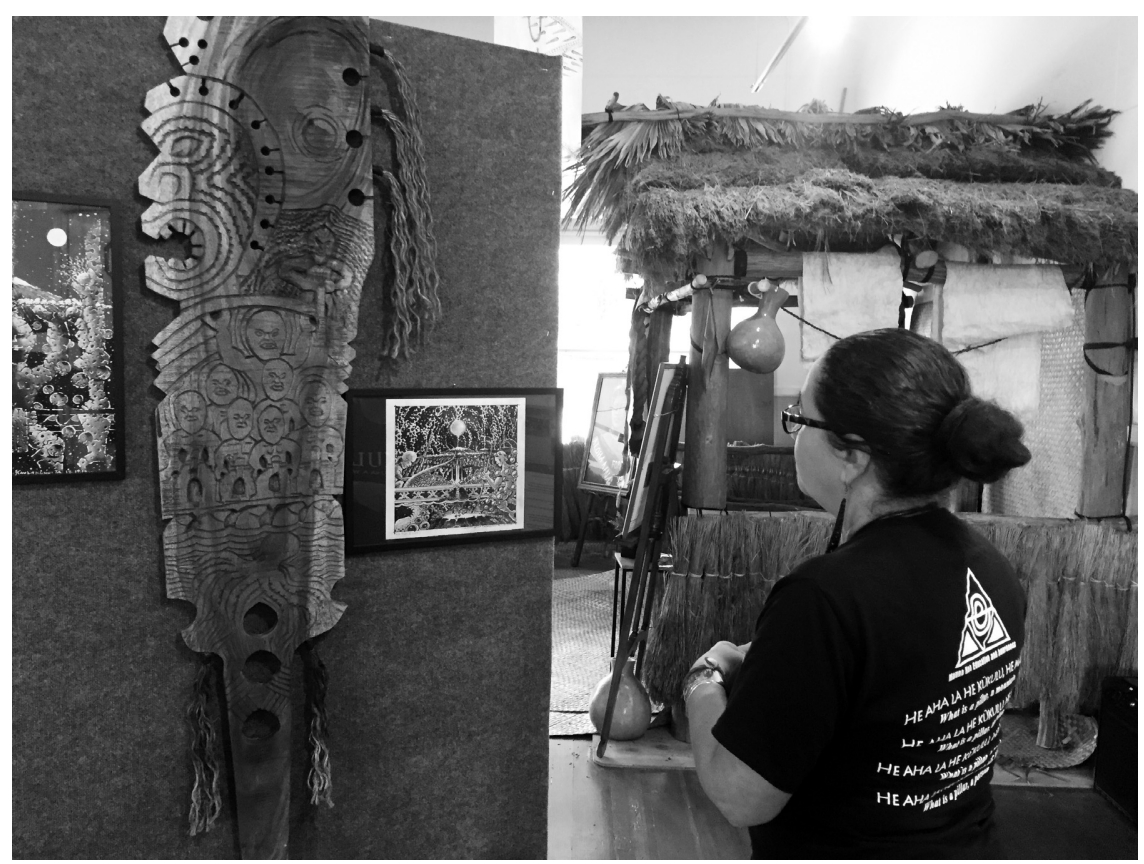

FIGURE 5.3 Pua Case with Kūkia'imauna and Hale Kūkia'imauna II in background. 
care for - even curate - them after, until the next time they are needed. Then they are called into action through song and prayer, through ceremony. During the 2019 protest the Kü images were present on the mauna until the arrival of the Makahiki season, which is signalled by the appearance of Makali' $i$ (Pleiades) in the night sky in November. At that time, the complementary ki'i of Lono replaced Kū.

The season has to be right, which is just the catch, as well as a provocation to think more about the stratigraphy and folds of living tradition. The Kū tradition is layered, to be sure, but it is not uniformly sedimented (Tengan 2014). Certain features of it break to the surface of the present if the need is great enough. Invention of/and/or tradition. None of this gets at the Hawaiian context, and I suspect this is true for most if not all settings of robust indigeneity. Kù is hardcore traditional. But his priests are long dead, and his appetite for human sacrifices and flesh appears sated (Valeri 1996). Today, he is called forth by young activists who command Hawaiian language and protocol, and who face a different source and order of threats than their ancestors did (Kraft and Johnson 2018: 190). Moreover, in a seeming paradox, Kükia'imauna is called by the kia' $i$ at the same time that they announce and enact 'kapu aloha', their governing ethic of non-violence. ${ }^{9}$ Some observers of such innovation might wonder if such a Kū is anything but bluster, wishful thinking, and indigeneity gone wrong.

Admittedly, Kūkia'imauna does not map perfectly on his ethnographic predecessors. 'Authenticity', however, turns out to be a poor judge of character. So what do we make of this latter-day Kü? We might look to the ki'i (image). It is not as if the kia'i regard the image as Kükia'imauna in the flesh. Theirs is a theology of activation and focus - of calling and using, of inspiration and metaphor. Kùkia'imauna enables a ritual idiom of stark presence that is also a pragmatic technology not unlike a weapon, a way of focusing ritual rhetoric and action to desired ends, if those ends involve an enemy or a threat, but only if the season is right. Here is where analyses of contemporary indigeneity as watered-down tradition fall flat. Kū is changing, no doubt. But not beyond recognition, especially to those who risk calling on him. They still operate according to a schedule. This is not a move on my part to displace authenticity discussions from things to calendars. But timing is everything, at least for Polynesians. The endurance of seasonally configured ceremonial attention tells me that place, people, and the environment conduce here in a specific way and that their favoured expression of this is to say that Kū has his time and Lono (god of peace, playfulness, and related themes) has his.

\section{Crosswalk - the exception that keeps on giving}

The Mauna Kea crosswalk (see Figure 5.1) and its simulacrum in the exhibit exemplify Hawaiian genius twice over. In the first instance, the genius of the crosswalk was the way the kia'i harnessed efficacious protest to a ritual frame of memory making, all the while exploiting a loophole of the state. Anyone who 
has followed the Mauna Kea protests on social media has seen the crosswalk, whether they knew it or not. During the 2015 protests, it became the paradigmatic site for photographic rendering of protest-as-history. Namely, each $l \bar{a}$ (day), kia' $i$ who were on the mauna would take a picture of themselves in the crosswalk with a sign stating the day and other signs of the sort described previously. In this way the crosswalk was the site of a daily growing archive of resistance, showing who was there, how the discourse (signage) was shifting, and what the weather was doing.

But why the crosswalk? Early on in the movement the kia'i learned that they could not be arrested if they were in the crosswalk, which is a state-designated safe space for pedestrians, of course. For a period of time in 2015 this was the chief means of direct action for the kia' $i$ to stop construction vehicles from going up the mountain. In this way the crosswalk at the Visitor Center (9000 foot level) became ground zero for the protests and hence also the site of daily photographs. Subsequent to the protests, the State of Hawai'i engaged in a range of efforts clearly aimed at stifling future actions of a similar nature. It is hard to overstate the range of enterprises engaged in by the state, including promulgating 'emergency rules', new legislation criminalising protest, state agency policy changes such as those described with reference to the hale and ahu below, and sundry other tactics of the strong.

Perhaps the most banal of these acts took place in July 2017 when state crews erected a guardrail adjacent to the Visitor Centre, which blocked access to the primary gathering spot of the kia'i, Hale Kükia'imauna. In the same spot the crew painted over the crosswalk, literally erasing it from the mauna. The kia' $i$ were not to be outdone easily. In their second instance of cross-walking and back-talking genius, they made a portable one themselves out of rubber mats and paint. It was then installed in the Kūkulu exhibit, where it maintains its function as the site of daily photographs of the status of the ongoing protest. When I asked her if the portable crosswalk might make it up to the mauna, Pua Case laughed heartily: "Of course!" (Personal communication. Honoka'a. 12 January, 2019). I invite readers to theorise with me about this 'hyper-real' prospect, which is complicated and enriched by the fact that the simulacrum of a state apparatus functions theologically in a Hawaiian way, being called into action for a particular purpose. Kūkia'icrosswalk?

\section{Hale Kūkia'imauna I and II}

On 27th February, 2018, I saw a curious Facebook post circulating among some of my Hawaiian acquaintances. It was a picture of Billy Freitas, my friend and sometimes collaborator, cutting trees in Waipi'o Valley. The caption mentioned "traditional hale building knowledge". ${ }^{10}$ I wondered, where and why is Billy building a new hale? Such construction would indicate preparations for a significant event. The next day the answer was as clear as it was unexpected: Kükulu. Billy and Lanakila Mangauil were working with others to build a traditional 
Hawaiian ritual house inside the exhibit, which was set to open only days from then. A Facebook post from the Hawaiian Cultural Center of Hāmākua had a picture of Billy and others building a more-or-less life-sized version of Hale Kükia'imauna, the headquarters of the kia'i during the protests, a site of much ritual action and numerous arrests. The 'replica', though not as long as the original, was at least as stout. I called Billy to check in and hear the story. Interesting to me, he reported having to seek out some old friends who knew particular building methods outside his considerable experience, in that way keeping a specialised knowledge in practice.

As with the crosswalk, the new hale raises compelling questions about objects and their simulacra, about labour and representation, and about houses within houses. The latter function, of archiving a house, is not idle museumification. It is also anticipatory. The Department of Land and Natural Resources (DLNR), the state entity with jurisdiction over the land on which the 'original' hale sits, was then in the process of promulgating new policies and rules regarding the building of 'unauthorised structures' and one component of their new plan is to deem it retroactive and thus applicable to the hale. In this frame, the urgency of Billy's labour is more legible. Indeed, as I describe later, the state subsequently removed the hale on 20th June, 2019, in a major sweep of the mauna.

Several ahu (stone altars/offering sites) on the mauna have received attention

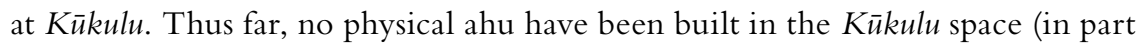
due to the weight-bearing limitations of the floor), but future sites of the exhibit may well entail the building of ahu. For now, the ahu of Mauna Kea are remembered at Kukvulu through words and images. The exhibition includes homage to ahu past, present, and absent. I have written about this history elsewhere, so I will be brief here (Johnson 2018). Suffice it to say that ahu construction on Mauna Kea is a storied affair, with episodes ranging from the ancient past to the almost certain future. Ahu quite literally dot the mountain, from sea level to the very summit. They are recorded in myth, history, and in the archaeological record. More important for my analysis, they function as a circuit whereby Hawaiians and allies follow ritual paths. Specific paths vary according to practitioners, purpose, and destination, but they all share common features. The ahu serve as protocol way stations, places to stop, regroup, and 'set intentions'. Modest offerings of libations and objects ('awa [kava], salt, bundled leaves) and words (prayers, songs, chants) are made before setting off to the next destination, frequently another ahu further up the mauna.

A feature that many ahu - past and recent - share is that they have been built in times of struggle. In such moments, or in commemoration of such moments, ahu focus collective will and become sites of articulation of joint purpose, often conveyed in the idiom of devotion (to a place, a deity, a lineage, and the intersection of these). In short, they are born of conflict and anchor specific people to places they regard as theirs or, what is functionally the same in a Hawaiian way, their kuleana (responsibility or obligation). One site, Ahu o Kauakoko, was bulldozed by the state in 2015. This fate was then shared by the ahu at the 
TMT site. ${ }^{11}$ Here the State of Hawai' $i$ constitution falls flat in practice, as does a sorry history of U.S. jurisprudence relative to indigenous places and things. Hawaiians are ritually stubborn and aesthetically driven, so no amount of state arrogance or ignorance is likely to deter ahu construction and consecration for long. Indeed, during the 24th June, 2018 protest commemoration, a new ahu was built and consecrated on the mauna, and the 2019-2020 protest has resulted in the same practice.

\section{North American and transnational connections}

An eye-catching aspect of Kükulu is the way it calls forth connections to other sites of recent protest actions, especially in North America. Hawaiians have a long history of working with American Indian and First Nation groups on various causes and consider them to be relatives. Just how the stakes and strands of relationality are represented is precisely the kind of issue INREL has trained its attention upon in other contexts. Here my observations are primarily cast at the level of Mauna Kea-related actors and actions. The 2015 Mauna Kea protest preceded Standing Rock, for example, but not by much. Certainly a clear template for non-violent direct action campaigns was long established in North America prior to the Mauna Kea dispute. Already, then, we are addressing a setting of common and shared actions, tropes, as well as grooved pathways of travel between North America and the Pacific.

Hawaiians and Native Americans have shared in one another's protests. On Mauna Kea this was true early on, with visitors coming from various native nations. Once matters calmed on Mauna Kea, some Hawaiians returned the favour. By autumn 2016 several Hawaiians were living in the Stand Rock camps. Numerous others visited, including Pua Case, Hāwane Rios, and Andre Perez, all of whom have played central roles in the 2019-2020 protest. These connections and reciprocations are, I would argue, as central to contemporary Hawaiian indigeneity as many other far more local acts. Travel of this sort builds a grander sense of indigenous resistance and purpose, one that is not predicated on the success of any one action.

Beyond North America, connections and awareness have been fostered in such settings, including with Sámi and other people encountered at these fraught sites. Kükulu names and celebrates such exchanges. Photographs, signs, and clothing objects bespeak engaged indigeneity on the road. This is not a finished story. The back and forth continues. For example, in the summer of 2017, Lakota elder Arvol Looking Horse visited Mauna Kea for World Peace Day with a group of American Indians. ${ }^{12}$ Flowing the other direction, Pua Case has been working concertedly with LaDonna Brave Bull Allard to keep the Standing Rock agenda - namely, protecting water resources - in the public eye, especially through various social media campaigns. In return, Allard visited Mauna Kea in the early phases of the $2019-2020$ protest. ${ }^{13}$ 


\section{Local stones and global flows - the Hōkūle'a pohaku}

The final object in the installation that I wish to discuss here is a very welltravelled pohaku (rock). Its itinerary tells a story of maximally global indigeneity in a key that is at once micro-local (a hand-picked, vision-informed stone) and emphatically inclusive, even proselytising. The pohaku was chosen by Hāwane Rios, Pua Case's daughter, to travel on the Hawaiian ocean canoe, Hōkūle'a, on its Mālama Honua (Caring for Earth) voyage, which circumnavigated the globe from 2013-2018..$^{14}$ A product of the Hawaiian Renaissance, Hōkūle'a was built in the 1970s in part to demonstrate Polynesian navigational and sailing capacities. It is 'neo-traditional' in the sense that it incorporates modern materials and has a motor-powered escort craft (Finney 2003). But it is heartily Hawaiian in an abiding sense, which is most clearly registered by way of its crew's orientation to ritual protocol. Manifest in numerous ways, especially in settings of departure and arrival, Hōkūle'a is a veritable floating oasis of Hawaiian ritual comportment and symbolisation. The pohaku served metonymically in this capacity, providing the crew with a rock-strong reminder of home and serving as a tactile beacon of Hawaiianess in destinations afar. There it is, resting like Kükia imauna in the exhibit. It too may be recalled to duty in the future.

\section{Back on stage: the 2019 eruption}

As noted previously, on 30th October, 2018 the State Supreme Court ruled in favour for the TMT construction permit. It was a decision that relied heavily on the state's findings and documents, which in turn directly parroted positions and arguments proffered by TMT's legal team. The tainted nature of the decision caused considerable frustration and misgivings among the kia' $i$ and increased the scepticism of many Hawaiians about the state's ability to deliver justice to their community. In any case, this decision marked the end of the road for direct legal challenges to the project. Now the terrain shifted from the courts back to the mauna itself. When would an attempt be made to resume construction? How would the kia'i respond?

Matters festered in the winter and spring of 2019. I was fortunate to visit Kükulu in January. Pua Case and Lanakila Mangauil conveyed a sense of urgency at the time and the exhibit seemed more relevant than ever. During that trip I was able to 'go mauna' twice, once with Ku Ching, a long-time pro-Mauna Kea activist and kupuna, and once with Billy Freitas to document him conducting ritual protocol at the TMT site ahu (see Figure 5.4). I had served as a witness for Billy during the contested case hearing wherein I specifically addressed his role in building the ahu and caring for them subsequently. He and I had made a number of trips to visit them and for me to document Billy conducting ceremonies at the site, including with INREL team in July 2018. Now, with the Court ruling issued, this trip had a special significance. Due to his work schedule and other demands upon his time, Billy wasn't sure when he would be at the ahu next, 


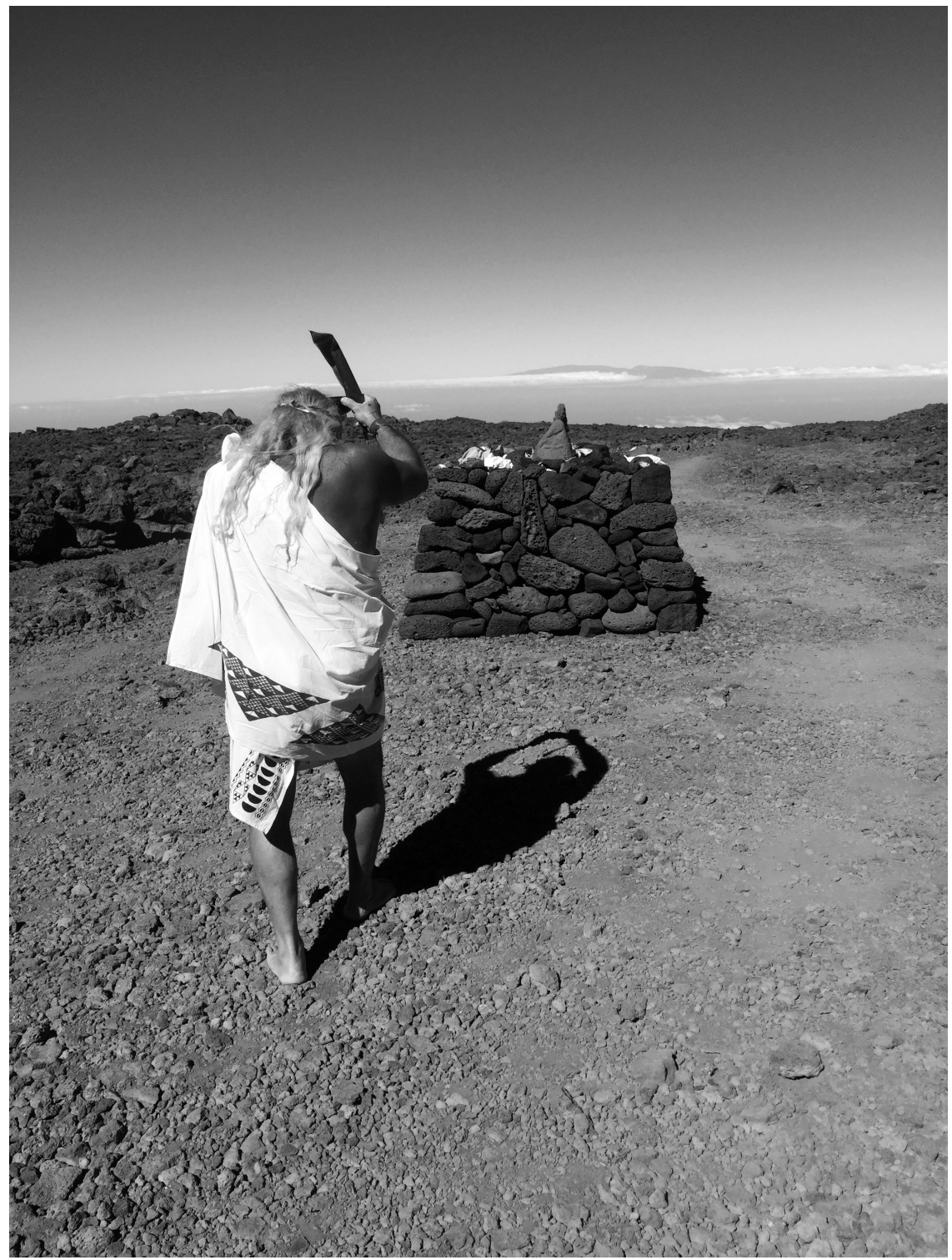

FIGURE 5.4 William “Billy” Freitas conducting protocol at Ahu Kūkia'imauna Ekahi.

and I wasn't scheduled to return soon. We both knew we might not see the ahu again, which proved to be true.

On 20th June, 2019, agents from the DLNR removed the ahu and Hale Kūkia imauna, declaring them to be "unpermitted structures". ${ }^{15}$ In defence of these actions, state representatives cited language from the Court to underscore their claim that the structures were not representative of sincere religion, but instead were mere relics of politically motivated protest that did not warrant 
constitutional protection. From the perspective of the kia'i community, these actions were egregious and highly inflammatory. Several kia'i, including Billy Freitas and Kaho'okahi Kanuha, were on the mauna during the middle-of-thenight removal of the structures. They responded in vigil, praying through the process. Their actions were live streamed by other kia' $i$, and once again social media helped to ignite a movement. Many in the Hawaiian community were outraged, especially by the removal of Hale Kükia'imauna, which was nowhere near the construction site, and by the removal of another protest-related structure the same night. In their view, the state was showing its hand: force would be used without regard for the sensibilities of cultural practitioners. But the plan did not pan out well. In some respects, it is fair to say in hindsight that the state created the very problem it sought to dampen. By removing cultural structures the state catalysed an intense cultural movement. The very next day social media was flooded with images of the ahu and the hale. That same day a new large ahu was constructed on the site of Hale Kūkia'imauna and another at the TMT site. Dislodging Hawaiian presence was not going to prove easy, especially when thousands of kia' $i$ arrived on the mauna less than a month later.

Meanwhile, based on a strong hunch that the mauna would erupt once again, I devoted my 2019 summer research time to being on Hawai'i Island. I arrived on 23rd June, just days after the state's removal of the ahu and hale. At first I enjoyed a comparatively quiet few weeks learning what I could about the present state of the movement and the mauna itself, which involved numerous hikes in solitude on its vast expanses and a few visits with practitioners to the TMT site to observe them ministering to the mauna and giving ho'okupu (offerings) at the provisional replacement ahu erected there. On one trip, which was made on 3rd July, my family and I accompanied Billy to the TMT site to check on the new ahu. We found that it had been removed. Billy calmly rebuilt a small ahu in its place and then proceeded to perform a ceremony in his modest style. This culminated in making ho'okupu. We documented his ceremony upon his request and participated in making ho'okupu. Our presence was in turn documented by a state ranger, a further indicator of escalating tensions on the mauna. In the days following, I began to hear rumours of imminent action by the state to prepare for protests.

Later that same week, the word from the state and on the street was that construction equipment for the TMT would be escorted up the mauna on 15th July. ${ }^{16}$ Things went into high gear on both sides. Police from several jurisdictions, including from other islands, were moving into place and the construction equipment was staged at an army base below the mauna. On the kia'i side, there was a large community-based strategy meeting on the 12 th, which took place ominously adjacent to Pu'ukohalā, Kamehameha's famed war temple. People were ready to mobilise and to strategise.

The next day, Saturday the 13 th, a pivotal event took place. Working with the Royal Order of Kamehameha, a highly respected group of elders, the kia'i established a basecamp for the impending movement at Pu'uhuluhulu, a small nature reserve. It is also the site of a prominent ahu used for ceremonies on behalf of the 
mauna and therefore has a long-standing significance for the kia'i. Moreover, it sits in a very strategic location at the entrance of the Mauna Kea Access Road, the only suitable road up the mauna for construction equipment. Crucially, and of signal importance for our purposes, the camp was established as a pu'uhonua, which means sanctuary or place of refuge. This is a specifically religious designation with a deeply traditional genealogy that also carries an undeniable political valence. Going far back in Hawaiian history, pu'uhonua were places one fled to in order to gain relief from political foes and physical struggle, among other reasons. ${ }^{17}$ Mobilisation of a potent Hawaiian trope as a means to name the camp and its ethos could not have been more apt. This stroke of cultural genius troubled the state's facile habit of distinguishing the religious from the political and gave living example to how these forces are often one in the same, especially in moments of cultural crisis.

Sunday the 14th was declared a day of ceremony at Pu'uhonua o Pu'uhuluhulu, with elaborate protocol (prayer, songs, and dance) every hour from sunrise to sundown. This commitment to ceremony set the tone of the movement internally and conveyed an outward facing message that has been profoundly efficacious. I arrived at $\mathrm{Pu}$ 'uhuluhulu mid-afternoon to witness the ceremonies. The amount of activity on the mauna immediately captured my attention, as did the peacefulness of Pu'uhonua o Pu'uhuluhulu, despite the numbers of people who had gathered, many for the long haul with camping gear and bail money. Milling about through the crowd and seeing many old friends, I was struck by the diversity of Hawaiians at the camp. While 'the usual' folks were there - the core kia'i from the 2015 protests, parties to the various legal proceedings, and other long-time supporters - numerous others were there as well, including hula dancers from various schools, chanters, academics, and many, many everyday Hawaiians. It was abundantly clear from the very first days of the Pu'uhonua that the work of holding space, including that performed by Kükulu, had been a success. A community had been fostered, and now it was mobilising. What struck me most was the way this collective was represented in ritual terms, with a nearly seamless flow from highly complex chanting and hula by some, to comparatively simple forms of worship by others. This was an eclectic movement that demanded supple ceremonial sensibilities and actions from its constituents. This collaborative ritual way-finding has become a hallmark of the movement, about which I say more later.

As more and more people streamed in from Hilo and Kona that evening, there was an intensity in the camp that bespoke anxiety about expected police presence in the morning but also reflected resolve and the already considerable momentum of the kia'i. My travelling companions and I obeyed the harsh instructions to be up at 2:30 a.m. in order to be organised and in place on the Mauna Kea Access Road, which was to be blockaded, before the police arrived. Over the short period we had tried to sleep, the camp had grown yet again, with cars lined up far down the highway from the Pu'uhonua. The kahea (call) had gone out, and the community responded. Infrastructure was already being 
developed in the camp: a large kitchen tent, a medic tent with a sizable group of volunteers, a strategy tent, a kūpuna (elders) tent, portable toilets, and a road crossing-guard station were all in place by the early morning of the 15 th, and the people in the camp had been self-assigned into three contingents: 'arrestable' (red armband), 'arrestable if needed' (yellow), and 'not arrestable' (green). This level or infrastructure and personnel organisation prefigured the kind of strategic acumen possessed by the group collectively that would be on display day after day for the coming weeks. The state, it became clear, had no idea how organised and disciplined the kia'i would be.

Central to their discipline was the ethic of kapu aloha (non-violent action), which had been so formative in 2015, and which had figured so centrally in the messaging of the Kükulu exhibit. Over and again in the camp meetings this was emphasised. Maintain the high ground or leave, we were all told. To facilitate the role of kapu aloha, Pua Case let the community know that a group of people would be designated to wear blue kapu aloha shirts and that they would serve to assist people in whatever capacity, but primarily to make sure kapu aloha was abided by at all times, including through a prohibition on drugs, alcohol, and any form of violence. This emphatic attention to kapu aloha has traditional sources, but it is also strategic insofar as it is the group's primary means for controlling media optics and, relatedly, for making sure conflicts with the state do not escalate and become an unwinnable contest of force.

Once we gulped down our coffee and made our way to the road, we became aware of the day's primary form of direct action. A core group of eight kia'i, including several professors and some long-time activists, had chained themselves to a cattle guard that crosses the road. Other 'reds' were instructed to occupy the road in front of them to slow the progress of the police. Frankly, I found this tactic potentially dubious, as a similar blockade recently deployed on Maui, during a telescope controversy there, had been overcome by the police. ${ }^{18}$ But the morning wore on with the police keeping some distance and only a small group approaching the kia'i chained to the cattle guard. Meanwhile, the ranks of the kia'i grew by the hour in ways few expected. By midday there were hundreds of protestors on the mauna whereas the police force was comparatively small, possibly by design insofar as the state was likely reluctant to have the media broadcast images of an outsized police force arresting kia'i. In any case, by late afternoon the police received orders to back down for the day. At that moment it seemed like a very temporary victory. In hindsight, it was a day that emboldened the protectors and gave them a chance to implement phase two of their strategy.

Phase two is still in progress as I write and it is a testimony to strategic foresight and endurance. On the morning of Tuesday the 16th, after pule (prayers) and oli (chants), a line of küpuna (elders) took up a position in the Access Road. It was announced to the assembled crowd that the kuppuna wished to be arrested. Regardless of the colours of our arms bands, the remainder of us were instructed not to interfere with their arrests. Additionally, we were instructed to remain silent so that the respective kūpuna could address the police and the crowd with 
their mana'o (thoughts) as they were taken away. Somewhat surprisingly, the day passed without incident and with much ceremony and strategising.

On Wednesday the 17th, the kuppuna line was again in the road, this time fortified by other kūpuna who came out to be arrested, including some very prominent members of the community with considerable state-wide visibility. These included a trustee of the Office of Hawaiian Affairs, several senior professors, famous musicians, renowned hula teachers, long-time activists with credentials going back to the struggle over Kaho'olawe in the 1970s, and a highly respected religious leader who had not previously been particularly visible among the ranks of the kia'i, Pualani Kanaka'ole Kanahele. Revered by many as a singular icon of living Hawaiian religion, Kanahele's presence marked a shift in the credibility of the movement for those outside its core group. Her presence corresponded with a swelling of the camps and with heightened media coverage of the protests, which amplified tremendously with the arrests that day of 38 kūpuna, some of them in wheelchairs or otherwise struggling with health issues. The media optics of that afternoon profoundly favoured the kūpuna, especially when more than a hundred wahine (women) entered the road to prevent further arrests, singing in arms-locked unison for hours in the face of riot-gear donning police. By late afternoon, the police backed off yet again.

Two days later Governor Ige announced an "Emergency Proclamation" for the mountain, saying he had received reports of drugs, alcohol, and other health risks in the camps. ${ }^{19}$ These unsubstantiated claims provoked a strong reaction from those in the camps, but also from some politicians and other observers. ${ }^{20}$ The tide continued to turn against the state and TMT. In just a few short days the kia'i succeeded in establishing a camp and a sacred discourse to go with it, stalled the police on several occasions, and generated public sympathy by having willing kūpuna be arrested for the cause (Figure 5.5). Meanwhile, the state bungled at every turn, enabling the kia'i to dig in. By Thursday of that week the Pu'uhonua infrastructure was all the more substantial and a sub-camp was developed at the küpuna line in the road. They were not going anywhere.

Of direct relevance to the INREL project, what happened next was decisive. The kia'i did not take a defensive posture or rest. They invested energy in consolidating the message that the movement was 'in ceremony' (cf. Johnson and Kraft 2018). Their messaging insisted that this was a ritual event in a sacred space, and this message was conveyed and reinforced through highly mediatised and translatable actions. Three times a day, every day, for now more than five months there has been 'full protocol' in the road in front of the kūpuna tent. Led by members of the Kanaka'ole Kanahele family and other experts, including Pua Case, this ceremony begins with traditional chants, which are followed by songs, prayers, and hula. The core pattern was set early on by high-level practitioners, but each ceremony involves some improvisation depending on who is present, weather conditions, and so forth. Some recently composed chants and songs have been central to the ceremonies as well, including ones that have figured in the $K \bar{u} k u l u$ displays, demonstrating the living quality of traditions on the mauna. 


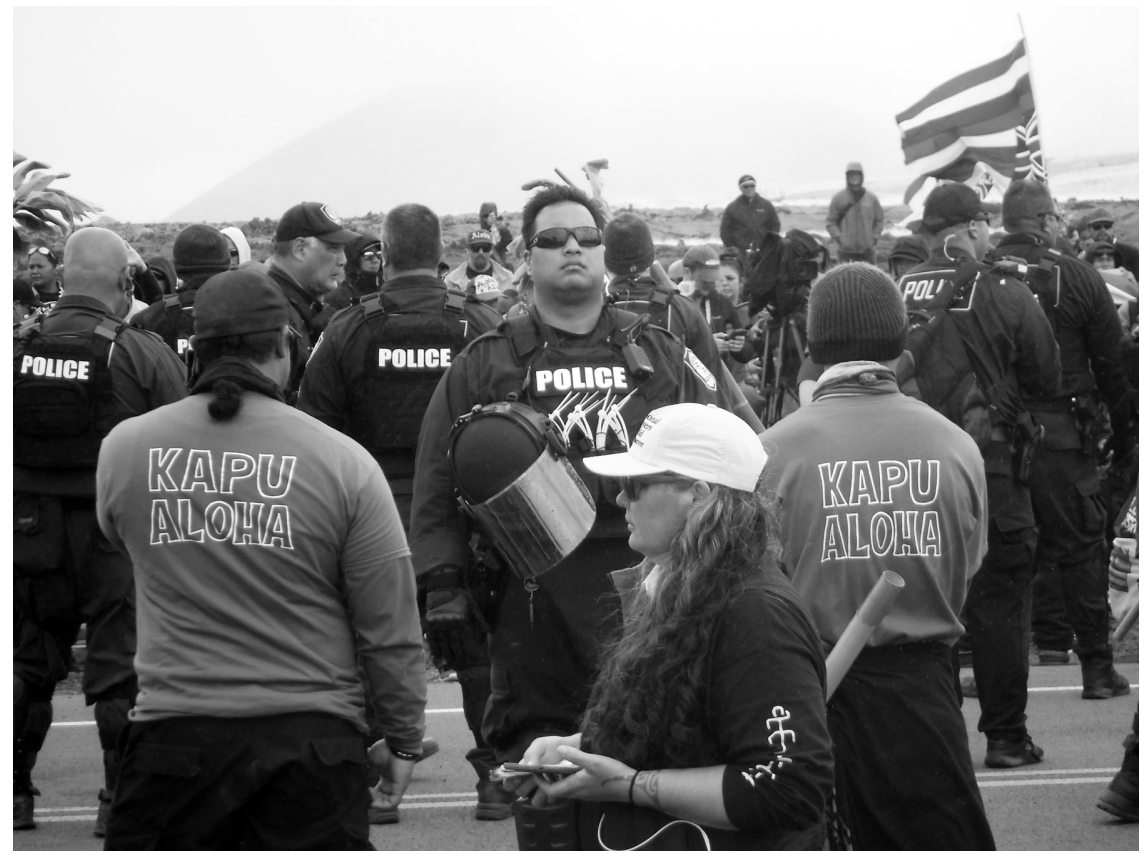

FIGURE 5.5 Police action and kapu aloha on July 17, 2019.

Chief among these is $K a^{\prime} i K \bar{u} k u l u$, the oli used as the epigraph for this chapter, which has been featured on t-shirts across Hawai' $i$ and now is the closing chant and hula of a generation-shaping ritual.

Redolent of ceremonial forms at Standing Rock, each day during ceremonies formal protocol is held for visiting dignitaries and other guests who present offerings and gifts, including songs, dances, and flags. Media outlets have broadcast images of the ceremonies on a regular basis, including of visiting superstars such as Dwayne "The Rock" Johnson and Jason Momoa paying homage to the mauna and the kupuna. It is safe to say that the unfolding events on Mauna Kea are unprecedented in terms of numbers of people involved, media reach, and religious innovation. ${ }^{21}$ Here I mean innovation not in the sense of mere invention, but the capacious manner by which tradition has been deployed and reshaped in and as real-time means for addressing the needs of the people, politically and spiritually.

\section{Conclusion: engaged indigeneity and indigenous religion(s)}

Engaged indigeneity is supple, persistent, and resistant to the truncating effect of authenticity discourses, and performed in many registers. Further, as I hope to have made clear by way of Kükulu and its relationship to the 2019-2020 protests, engaged indigenty functions on and off stage. Much more could be said about 
engaged indigeneity, of course, but these features strike me as particularly relevant for understanding the work of indigenous religion(s). With reference to Mauna Kea, one could not begin to make sense of the daily ceremonial protocol during the 2019-2020 protest, for example, without accounting longitudinally for the ebbs and flows of the movement and how it was animated along the way by various people who performed a range of roles and drew upon a diversity of experiences and cultural capacities to do so. If one charts the trajectory of Hawaiian care for Mauna Kea, it becomes clear that several strands of religious practice have been individually and collectively important. My point here is not to give a full account of these different styles of Hawaiian religiosity, but rather to call attention to the ways they are jointly expressed on Mauna as a unified voice.

The analytical usefulness of the INREL construct 'indigneous religion(s)' is apropos here. As noted previously, at least three kinds of Hawaiian religious practice are evident in the daily protest protocol. Examples include: highly formalised hula and chanting as guided by revered cultural teacher Pualani Kanaka'ole Kanahale, her family, and her students; Mauna Kea-specific forms of contemporary practice, including songs, chants, and slogans, led by Pua Case and her community; and grassroots, site-specific forms of prayer and offering made by people such as Billy Freitas who have comparatively little formal training but who have tremendous experience on the land and garner respect accordingly. The three kinds of practice I have sketched here have different participants and audiences off the mauna, and these bespeak variable degrees of resources they can command and the differential influence they enjoy in other contexts. I do not mean to overstate their differences, but they do operate in different spheres and at different scales. One could go so far as to say, schematically, that they constitute diverse Hawaiian religions - plural, in the INREL sense.

Collectively on Mauna Kea, however, I would argue that they have been functioning together as a form of Hawaiian religion, singular. Representatives of each group have coordinated their practices and accomodated one another. The very protocol for each day illustrates this beautifully. ${ }^{22}$ But working together to establish a shared ritual format does not itself render these diverse Hawaiian religions into a singular expression of Hawaiian religion. It is the formal feature of this convergence that is so powerfully unanimous. Namely, the various ritual articulations consistently convey a macro-order message: "The mauna is sacred and we are its protectors". The persuasive capacity of the movement is found just here. When such a range of practitioners coordinate their message, and when that message is announced from the literal and moral highground, they make the strongest possible claim for indigneity in a religious key. In doing so, they also cast their sacred claims at a level that opens up translational possiblities with other indigenous communities and causes, and with allies.

In closing, I would like to expound a bit more about how the INREL framing of indigenous religion(s) has facilitated my interpretation of what is happening on Mauna Kea. Early in our endeavour, the INREL team set out a model of 
religion/religions and stipulated an analytical frame focused on scaling dynamics as means best to understand their relationship (between local-specific 'religions' and more general and increasingly shared 'religion'). In some of our projectrelated publications we settled on the device 'religion(s)' in an attempt to convey both modalities and the relationship between them (Johnson and Kraft 2017). What we found compelling by way of the religion(s) construct was confirmation of the rhetorical and communicative savoir faire of indigenous people who use religious idioms and ritual actions in a variety of settings to confront challenges and expand their audience reach. Form, not content, was the answer to the question we posed, with the particular twist here being that the formal categories pertaining to religion marshalled by indigenous actors frequently are ones commonly invoked by scholars of religion: e.g., ceremony, story, prayer, and above all, sacred. What we found is that translation and scaling of concerns happen less often by means of generalising content and more by way of formal assertions.

Here the work of analysis is to backtrack from substantive expressions to assess the rhetorical function of the formal claims being instantiated and advanced. Comparison is critical in this mode, as one needs to consider multiple instances of such discourse to begin to see how this rhetoric does its work. 'THIS (thing, act, word) is sacred', we came to appreciate, is a means to say it is a group's highest register of concern, engagement, and commitment and that no mundane reality is a suitable corollary or substitute. On Mauna Kea, it is this inflection of indigenous religion that is on display every day of the protest and it is precisely the form of religion that other people are resonating with and responding to.

Thus transacted, sacred comes to signify a working agreement between diverse indigenous people along the following lines: various culture-specific traditions that animate such claims stand in a more or less metaphorical relationship to one another. Sacred here is not the noumenal 'really real' (though some might intend that, too), but a way of marking and remarking upon highest order agreement and congruence: an assertion about diverse indigenous spiritual realities being comparable or parallel in contrast to those of the non-indigenous world that are perceived to be at odds with the former. Sacred, in this mode, is a beacon of sorts on the global seas of indigeneity, enabling indigenous peoples to locate and identify with indigenous others elsewhere, what Kraft and I have called "distant selves" (Johnson and Kraft 2018: 7-8).

In this way, sacred - and other ways of indexing singular indigenous religion - functions as a claim about claims in order to insist on a superior and shared register of understanding and engagement. This indigenous inflection of the sacred, I am persuaded, is strongly consistent from micro-local to macro-global invocations. It might be said that my observation is banal insofar as many if not all invocations of the sacred could be said to entail highest order positionings of ontological, cosmological, and moral claims. I agree, but would add that overwhelmingly - at least in contexts of indigeneity directly shaped by 
European-American colonisation, technology, and market forces - contemporary indigenous sacred claims constitute a contrastive discourse vis-à-vis the presumed failure of broader society's extractive and alienating treatment of nature and indigenous peoples themselves. Sacred here refers to the entities that make up the environment itself, from earth to sky, and to a relationship of mutual care between these entities and humans.

However, even as I stretch to stipulate formal features of indigenous religion(s), I find myself making potentially unsustainable generalisations. What of indigenous religions not directly impacted by European-American historical forces or subject to the habits of European-American scholarly enquiry? This question unsettles my confidence, nudging me to retreat to the specifics of familiar ground, if now differently understood. That is one of the productive features of a comparative and collaborative project on its best day - one stretches to find resemblances and similarities (of phenomena and possibly also of causes, consequences, meaning, and significance), but in this very act is chastened by stubborn particularities and unyielding differences. Comparison, of course, is thus best approached as a means to trouble rather than simplify conceptual maps, a point Jonathan Z. Smith (2004), among others, has long insisted upon. Having collective experiences in several highly diverse settings with the INREL team certainly has driven home the point for me.

\section{Notes}

1 Used by permission from Pualani Case. A video of the chant, along with all of the protocol chants used in the Mauna Kea protest ceremonies of 2019-2020, can be found at www.puuhuluhulu.com/learn/protocol (accessed 7 February, 2020).

2 For an account of Mangauil's actions, see: www.nytimes.com/2016/10/04/science/ hawaii-thirty-meter-telescope-mauna-kea.html (accessed 24 September, 2019).

3 For a news account, see, e.g., "Telescope protestors pile rocks in the road", Honolulu Star-Advertiser, 24 June 2015.

4 For a complete record of the primary legal and administrative documents pertaining to the dispute, see http://dlnr.hawaii.gov/mk/documents-library/.

5 For the court's decision, see https://law.justia.com/cases/hawaii/supreme-court/2018/ scot-17-0000777.html

6 The relevant passage is Article 12, Section 7: "The State reaffirms and shall protect all rights, customarily and traditionally exercised for subsistence, cultural and religious purposes and possessed by ahupua'a tenants who are descendants of native Hawaiians who inhabited the Hawaiian Islands prior to 1778 , subject to the right of the State to regulate such rights". (emphasis added) (1978).

7 To give but one example, each major island has a burial council charged with administration of the state burial law. These councils are frequently quite outspoken and effective but for many years have been hampered by insufficient state funding and other administrative shortcomings. For a rich account of the successes and failures of the burial councils, see Nāone Hall (2017).

8 Used by permission from Pualani Case. The core refrain of the Hawaiian language version of the chant has been performed in call-and-response fashion at the end of the thrice daily aha (ceremonies) during the 2019-2020 protests. See later in this chapter. 
9 For an excellent discussion of the religious and political sources and implications of kapu aloha, see this video of Pua Case and Andre Perez filmed at the 2019 protest site: www. facebook.com/watch/?v=2350192721897375 (accessed 22 September, 2019).

10 Hawaiian Cultural Center of Hāmākua, Facebook post. 27 February, 2018.

11 See: www.bigislandvideonews.com/2019/06/20/video-kanuha-arrested-on-mauna-keaas-police-dismantle-ahu/ (accessed 15 September, 2019) and www.hawaiinewsnow. com/2019/06/20/authorities-dismantle-structures-mauna-kea-set-up-by-tmt-protesters/ (accessed 15 September, 2019).

12 See www.huffpost.com/entry/lakota-chief-to-honor-hawaiian-sacred-sites-in-2017_b_ 5860424ae4b068764965bd32 (accessed 24 September, 2019).

13 For an account of Allard's connections to the Mauna Kea movement, see: https:// howzitkohala.com/2019/07/28/standing-rock-yields-insight-on-mauna-kea-byandrew-gomes/ (accessed 23 September, 2019).

14 See: www.hokulea.com/worldwide-voyage/

15 See: https://governor.hawaii.gov/newsroom/latest-news/office-of-the-governor-newsrelease-state-issues-notice-to-proceed-for-thirty-meter-telescope-project/ (accessed 24 September, 2019).

16 See: https://governor.hawaii.gov/newsroom/latest-news/governors-office-joint-newsrelease-thirty-meter-telescope-set-to-start-construction/ (accessed 24 September, 2019).

17 See: www.bigislandvideonews.com/2019/07/13/puu-huluhulu-to-be-designated-apuuhonua-tmt-opponents-say/ (accessed December 20, 2019).

18 See: www.nbcnews.com/news/asian-america/6-arrested-during-protest-maui-solartelescope-n789156 (accessed 24 September, 2019).

19 See: https://governor.hawaii.gov/wp-content/uploads/2019/07/1907086-Mauna-Kea. pdf (accessed 24 September, 2019).

20 For example: www.thegardenisland.com/2019/07/23/hawaii-news/councilmemberscall-for-ige-to-reverse-mauna-kea-proclamation/ (accessed 24 September, 2019).

21 For a media account of the religious aspects of the protests, see: www.ncronline.org/ news/environment/hawaii-mauna-kea-protectors-fight-telescope-project-prayer (accessed 12 September, 2019).

22 I encourage readers to watch videos of the ceremonies, which are archived on several Facebook sites, including Pu'uhonua o Pu'uhluhulu, Kāko“o Haleakalā, and Kanaeokana.

\section{References}

Brown, Marie Alohalani. 2017. "Mauna Kea: Ho'omana Hawai'i and Protecting the Sacred". Journal of the Society for the Study of Religion, Nature, and Culture 10 (2): 150-169.

Casumbal-Salazar, Iokepa. 2017. “A Fictive Kinship: Making 'Modernity', 'Ancient Hawaiians', and the Telescope on Mauna Kea”. Native American and Indigenous Studies 4 (2): $1-30$.

Clifford, James. 2004. “Traditional Futures”. In Questions of Tradition, edited by Mark Phillips and Gordon Schochet. Toronto: University of Toronto Press, 152-168.

Finney, Ben. 2003. Sailing in the Wake of the Ancestors: Reviving Polynesian Voyaging. Honolulu: Bishop Museum Press.

Fujikane, Candance. 2019. "Mapping Abundance on Mauna a Wākea as a Practice of Ea". Huli: Multidisciplinary Research on Hawaiian Well-Being 11 (1): 23-54.

Gonzales, Angela. 1998. "The (Re)articulation of American Indian Identity: Maintaining Boundaries and Regulating Access to Ethnically Tied Resources". American Indian Culture and Research Journal 22 (4): 199-225.

Goodyear-Ka'oppua, Noelani. 2017. "Protectors of the Future, Not Protestors of the Past: Indigenous Pacific Activism and Mauna a Wākea”. South Atlantic Quarterly 116 (1): 184-194. 
Goodyear-Ka'ōpua, Noelani, Ikaika Hussey, and Erin Kahunawaika'ala Wright (eds.). 2014. A Nation Rising: Hawaiian Movements for Life, Land, and Sovereignty. Durham and London: Duke University Press.

Hall, Stuart. 1986. "Gramsci's Relevance for the Study of Race and Ethnicity". Journal of Communication Inquiry 10: 5-27.

Johnson, Greg. 2014. "Bone-Deep Indigeneity: Theorizing Hawaiian Care for the State and Its Broken Apparatuses". In Performing Indigeneity: Global Histories and Contemporary Experiences, edited by Laura R. Graham and H. Glenn Penny. Lincoln and London: University of Nebraska Press, 247-272.

Johnson, Greg. 2017. "Materialising and Performing Hawaiian Religion(s) on Mauna Kea”. In Handbook of Indigenous Religion(s), edited by Greg Johnson and Siv Ellen Kraft. Leiden: Brill, 156-175.

Johnson, Greg. 2018. "Ritual, Advocacy and Authority: The Challenge of Being an Irreverent Witness". In Irreverence and the Sacred: Critical Studies in the History of Religions, edited by Hugh B. Urban and Greg Johnson. New York: Oxford University Press, 131-154.

Johnson, Greg and Siv Ellen Kraft. 2017. "Introduction". In Handbook of Indigenous Religion(s), edited by Greg Johnson and Siv Ellen Kraft. Leiden: Brill, 1-24.

Johnson, Greg and Siv Ellen Kraft. 2018. "Standing Rock Religion(s): Ceremonies, Social Media, and Music Videos". Numen: International Review for History of Religions 65: 499-530.

Kauanui, J. Kēhaulani. 2013. "Precarious Positions: Native Hawaiians and U.S. Federal Recognition". In Recognition, Sovereignty Struggles, and Indigenous Rights: A Sourcebook, edited by Amy E. Denouden and Jean M. O'Brien. Chapel Hill: University of North Carolina Press, 314-336.

Kraft, Siv Ellen and Greg Johnson 2018. "Protective Occupation, Emergent Networks, Rituals of Solidarity: Comparing Alta (Sápmi), Mauna Kea (Hawai'i), and Standing Rock (North Dakota)". In The Bloomsbury Handbook of Religion and Nature: The Elements, edited by Laura Hobgood and Whitney Bauman. London and New York: Bloomsbury Academic, 185-196.

Li, Tania. 2000. "Articulating Indigenous Identity in Indonesia". Comparative Studies in Society and History 42: 149-179.

Merry, Sally Engle. 2000. Colonizing Hawai'i: The Cultural Power of Law. Princeton: Princeton University Press.

Nāone Hall, Dana. 2017. Life of the Land: Articulations of a Native Writer. Honolulu: 'Ai Pohaku Press.

Niezen, Ronald. 2003. The Origins of Indigenism: Human Rights and the Politics of Identity. Berkeley: University of California Press.

Osorio, Jonathan. 2002. Dismembering Lāhui: A History of the Hawaiian Nation to 1887. Honolulu: University of Hawai'i Press.

Povinelli, Elizabeth. 2002. The Cunning of Recognition: Indigenous Alterities and the Making of Australian Multiculturalism. Durham and London: Duke University Press.

Scott, James C. 1990. Domination and the Arts of Resistance: Hidden Transcripts. New Haven: Yale University Press.

Smith, Jonathan Z. 2004. Relating Religion: Essays in the Study of Religion. Chicago and London: University of Chicago Press.

Tengan, Ty Kāwika. 2008. Native Men Remade: Gender and Nation in Contemporary Hawai $i$. Durham and London: Duke University Press. 
Tengan, Ty Kāwika. 2014. "The Return of Kū? Re-Membering Hawaiian Masculinity, Warriorhood, and Nation". In Performing Indigeneity: Global Histories and Contemporary Experiences, edited by Laura R. Graham and H. Glenn Penny, 206-246.

Teves, Stephanie Nohelani. 2018. Defiant Indigeneity: The Politics of Hawaiian Performance. Chapel Hill: University of North Carolina Press.

Tweed, Thomas. 2006. Crossing and Dwelling: A Theory of Religion. Cambridge: Harvard University Press.

Valeri, Valerio. 1996. Kingship and Sacrifice: Ritual and Society in Ancient Hawaii. Translated by Paula Wissing. Chicago and London: University of Chicago Press. 